\title{
CpG methylation participates in regulation of hepatitis B virus gene expression in host sperm and sperm-derived embryos
}

\begin{abstract}
Aim: This study was undertaken to investigate relationship between hepatitis $B$ virus (HBV) CpG methylation and HBV gene transcription in sperm and sperm-derived embryos. Methods: HBV-infected patient sperm and HBV plasmid-transfected donor sperm were subjected to interspecific in vitro fertilization, methylation-specific $P C R$, bisulfite sequencing PCR, reverse transcription PCR and real-time quantitative PCR. Results: Positive methylation bands for CpG islands II and III in the HBV genome were observed in patient sperm but not in controls, and methylation percentages of CpG sites varied among different patient sperm samples. After fertilization, CpG sites were highly demethylated in embryos. Transcriptional levels of HBV $X$ and $S$ genes increased with decrease in $\mathrm{CpG}$ site methylation percentages. Conclusion: HBV CpG sites can be methylated in patient sperm before maturation. Methylation of CpG islands II and III participates in transcriptional regulation of HBV $X$ and $S$ genes, respectively, in sperm and sperm-derived embryos.
\end{abstract}

First draft submitted: 27 September 2016; Accepted for publication: 24 November 2016; Published online: 6 December 2016

Keywords: hepatitis B virus $\bullet$ methylation and gene expression $\bullet$ sperm and embryos

Hepatitis B virus (HBV) can invade the human male germline, and its DNA has been detected at various stages of spermatogenesis in patients with chronic HBV infection [1,2]. In 1985, Hadchouel et al. found presence of integrated HBV DNA sequences in patient sperm and assumed the possibility of true vertical transmission of HBV via the germline [3]. Thereafter, some studies detected that HBV DNA is able to integrate into sperm chromosomes of the patients and such HBV DNA-carrying sperm can enter oocyte to achieve normal fertilization [4]. After fertilization, the sperm-introduced HBV genes remain their function in replication and expression in embryonic cells [5-7]. It is worth mentioning that using FISH, the positive signals for HBV DNA were detected in both nuclei of individual two-celled embryo derived from the sperm carrying HBV genes, which suggested that the sperm-introduced HBV genes are able to replicate concomitantly with the host embryo genome, and the two viral gene copies segregated normally into the daughter cells during the first cleavage [5]. This mode of replication is semiconservative and completely different from the canonical replication mode of HBV particles (virion) through its life cycle including cccDNA formation [8,9]. Recently, Hu et al. collected 578 embryos from couples with at least one HBsAg seropositive partner. The FISH results showed that HBV DNA was present in $14.4 \%$ (83/578) of embryos, and the rates of HBV DNA positive embryos among the couples, in whom the woman, man or both partners were HBsAg seropositive, were $13.1 \%$ (57/436), $21.3 \%(16 / 75)$ and $14.9 \%$ $(10 / 67)$, respectively [10]. The increasing studies demonstrated that not only HBV but also the other viruses, such as HIV-1 and hepatitis $\mathrm{C}$ virus (HCV) are able to integrate into sperm genome of the patients and vertically transmit
ChengYao Zhong ${ }^{\ddagger}, 1$ Hui Lu ${ }^{\ddagger}, 2$, TingTing $\mathrm{Han}^{3}$, XiaoFang Tan ${ }^{2}$, PengHao $\mathrm{Li}^{3}$, JiHua Huang ${ }^{3}$, QingDong $\mathrm{Xie}^{2}$, ZhiWei $\mathrm{Hou}^{4}$, Ting $\mathrm{Qu}^{3}$, Yang Jiang ${ }^{3}$, Sheng Wang ${ }^{3}$, Lan $\mathrm{Xu}^{5}$, Ying Zhong ${ }^{3}$ \& TianHua Huang ${ }^{*, 3}$

${ }^{1}$ Faculty of Science \& Engineering, Paul Sabatier University-Toulouse III, Toulouse 31062, France

${ }^{2}$ Research Center for Reproductive Medicine, Shantou University Medical College, Shantou 515041, China 3 Jinxin Research Institute for Reproductive Medicine \& Genetics, Chengdu Jinjiang Hospital for Maternal \& Child Health Care, Chengdu 610066, China

${ }^{4}$ Key Laboratory of Birth Defects \& Reproductive Health of the National Health \& Family Planning Commission, Chongqing Population \& Family Planning Science \& Technology Research Institute, Chongqing 400020, China ${ }^{5}$ The First Affiliated Hospital, Shantou University Medical College, Shantou 515041, China

*Author for correspondence: thhuang@stu.edu.cn ${ }^{\ddagger}$ Authors contributed equally
Future $\%$
Medicine ${ }_{\text {part of }}$ fsg 
to embryos [10-18]. Because HBV has a potentially negative effect on male reproductive function and because dangerous infections can be transmitted to partners and newborns $[19,20]$, the mechanism underlying the regulation of $\mathrm{HBV}$ gene expression in sperm and embryos has attracted the attention of researchers.

The HBV genome contains four partially overlapping open reading frames (pre-S/S, corele, $X$ and $P$ genes) that are under the transcriptional control of four promoters (sp1, sp2, cp and $\mathrm{xp}$ ) and two enhancer elements (Enh I and Enh II). These effectors modulate the transcription and translation of seven different $\mathrm{HBV}$ proteins using distinct in-frame start codons [8,9]. DNA methylation, an important form of epigenetic modification, plays a crucial role in the repression of gene transcription, which is estimated to occur at approximately $70-80 \%$ of CG dinucleotides throughout the genome [21]. The remaining unmethylated CG dinucleotides are grouped into clusters (CpG islands) that are predominantly located in or near gene promoters [21]. A 3.2-kb partially double-stranded circular HBV genome was found to contain three CpGrich regions spanning the ATG start site for surface antigen gene (island I), Enh I with X-protein gene promoter (island II) and the ATG start site of polymerase gene (island III) [22-26]. It is well recognized that hypermethylation of CpG islands is involved in gene silencing at the transcriptional level [27]. However, the following points remain unclear. First, it is unknown what occurs when HBV genes are introduced into human sperm. HBV DNA is methylated in certain human somatic tissues, such as non-neoplastic liver tissues and $\mathrm{HBV}$-associated hepatocellular carcinoma tissue $[26,28]$, but it is not known whether it is methylated in human male germ cells. Next, in mammals, there are at least two developmental periods, in germ cells and in preimplantation embryos, in which the methylation patterns are reprogrammed throughout the genome [29,30]; thus, it is important to identify changes in methylation patterns that occur at $\mathrm{CpG}$ sites in the HBV genome during transmission of the virus gene from sperm to sperm-derived embryos. Finally, among the three $\mathrm{CpG}$ islands in the HBV genome, islands II and III are of particular interest because, in contrast with island I that is absent from approximately 50\% of $\mathrm{HBV}$ sequences isolated from patients residing in 48 different countries, these islands are conserved across genotypes and are present in all HBV sequences [2325]. Island II encompasses Enh I and the $X$ gene promoter, and island III is located upstream of the sp1 and sp2 promoters [23-25]. Whether CpG islands II and III participate in the regulation of the HBV $X$ and $S$ gene expression in sperm and sperm-derived embryos remains to be elucidated.
The aim of this study was to answer the aforementioned questions to increase understanding of the potential involvement of epigenetic modifications of $\mathrm{HBV}$ DNA in a novel mechanism of regulation of viral gene expression in human sperm and sperm-derived embryos.

\section{Materials \& methods}

\section{Subjects}

Eleven patients ranging in age from 22 to 38 years who sought fertility treatment at the hospital were clinically diagnosed as chronic HBV carriers by antigen-antibody combination assay (Supplementary Table 1). Eleven healthy donors ranging in age from 22 to 38 years were negative for $\mathrm{HBV}$ markers and selected as controls.

\section{Preparation of sperm \& oocyte, insemination \&} postinsemination cultures

Preparation of human motile sperm and zona-free hamster ova, insemination and post-insemination cultures were performed as described previously [5]. Inseminated oocytes were incubated for $24 \mathrm{~h}$ until formation of two-celled embryos.

\section{Plasmid methylation}

Unmethylated and methylated pBR322-HBV plasmids containing the full-length HBV genome were used in this study. Methylation of the plasmid was performed in a $50 \mu \mathrm{l}$ reaction mixture containing plasmid DNA $(0.5 \mu \mathrm{g} / \mu \mathrm{l}, 5 \mu \mathrm{l}), 10 \times$ NEBuffer $(5 \mu \mathrm{l}$; New England BioLabs, Beijing, China), S-adenosylmethionine (SAM; $1.6 \mathrm{mM}, 5 \mu \mathrm{l}$ ), CpG methyltransferase (M. SssI, $4 \mathrm{U} / \mu \mathrm{l}, 2 \mu \mathrm{l}$; New England Biolabs) and $\mathrm{H}_{2} \mathrm{O}$ $(33 \mu \mathrm{l})$. After incubation at $37^{\circ} \mathrm{C}$ for $1 \mathrm{~h}$, the reaction was stopped by heating at $65^{\circ} \mathrm{C}$ for $20 \mathrm{~min}$. DNA was purified by phenol-chloroform extraction and ethanol precipitation.

\section{Exposure of human sperm to plasmids}

Donor sperm samples were transfected with the unmethylated or methylated plasmid. Briefly, 100 $\mu \mathrm{l}$ of a transfection solution containing $2 \mu \mathrm{g}$ plasmid and $3 \mu$ FuGENE $^{\circledR}$ HD Transfection Reagent (Roche, Guangzhou, China) was prepared in sterile water and kept at room temperature for at least $15 \mathrm{~min}$. Sperm cells were collected and incubated in fresh Biggers-Whitten-Whittingham medium supplemented with $1.5 \%$ bovine serum albumin for capacitation. One hour later, the plasmid (final concentration of $1.5 \mu \mathrm{g} / \mathrm{ml}$ ) was added to capacitating medium. After exposure to the plasmid and an additional $3 \mathrm{~h}$ of incubation for capacitation, the sperm cells were washed five-times to remove the plasmid and were then used to fertilize zona-free hamster ova in vitro to obtain two-celled embryos. 


\section{Detection of plasmid transfection efficiency into sperm}

To measure the transfection efficiency of the unmethylated and methylated plasmids into sperm, a Nick Translation Kit (Roche, Basel, Switzerland) and Fluorescein-12-dUTP (Thermo Fisher Scientific, MA, USA) were employed. The two plasmids were labeled with fluorescein-12-dUTP by nick translation according to the manufacturer's instructions. Transfected sperm were detected by their green fluorescence and counted under a fluorescence microscope.

\section{CpG sites in islands II \& III in the HBV genome}

As reference sequences, three normal HBV sequences were obtained from GenBank of the National Center for Biotechnology Information (NCBI; accession numbers: EU871997, AY206384 and AY123424). The schematic structure of the $\mathrm{HBV}$ genome, including the $\mathrm{CpG}$ island distribution in the representative HBV genomic sequence, is shown in Supplementary Figure 1. Island II is located at nucleotides 1170-1669, which encompasses Enh I and the $X$ gene promoter and part of the $X$ gene. Island III is located at nucleotides 2298-2446, which is upstream of the sp1 and sp2 promoters. Primer pairs were designed using MethPrimer [31] to amplify a segment of island II (nt1249-1380) containing seven $\mathrm{CpG}$ sites and a segment of island III (nt2369-2480) containing eight CpG sites. The seven $\mathrm{CpG}$ sites in island II were located in the $\mathrm{X}$ promoter region near enhancer I, specifically at $-20,-42,-48$, $-68,-74,-100$ and -112 nucleotides, respectively, from the $\mathrm{X}$ promoter. The eight $\mathrm{CpG}$ sites in island III were located upstream of the $\mathrm{sp} 1$ and $\mathrm{sp} 2$ promoters, specifically at $-278,-296,-299,-301,-303,-316,-322$ and -327 nucleotides, respectively, from the sp1 promoter (Supplementary Table 2, Supplementary Figures 1 \& 2).

\section{Detection of methylation statuses of CpG sites} in islands II \& III in the HBV genome

A Universal Genomic DNA Extraction Kit (TaKaRa, Dalian, China) was used to extract DNA from sperm transfected with plasmids, as well as from sperm from the patients and controls and from sperm-derived embryos, according to the manufacturer's protocol. Bisulfite conversion of DNA was performed using an EZ DNA Methylation-Gold ${ }^{\mathrm{TM}}$ Kit (for sperm) or an EZ DNA Methylation-Direct Kit (for embryos; ZYMO, Orange, CA, USA) according to the manufacturers' instructions.

The PCR mixture contained bisulfite-modified DNA $(2 \mu \mathrm{l}), \mathrm{Taq}^{\mathrm{TM}}$ Hot Start $(12.5 \mu \mathrm{l}$; TaKaRa), the forward and reverse primers $(10 \mu \mathrm{M}, 0.5 \mu \mathrm{l}$ each) and $\mathrm{ddH}_{2} \mathrm{O}(9.5 \mu \mathrm{l})$. The PCR conditions were as follows: denaturation at $95^{\circ} \mathrm{C}$ for $3 \mathrm{~min} ; 39$ cycles at $94^{\circ} \mathrm{C}$ for
$30 \mathrm{~s}, 55^{\circ} \mathrm{C}$ for $30 \mathrm{~s}$ and $72^{\circ} \mathrm{C}$ for $1 \mathrm{~min}$; a final extension at $72^{\circ} \mathrm{C}$ for $5 \mathrm{~min}$; and storage at $4^{\circ} \mathrm{C}$. For methylation-specific PCR (MSP), bisulfite-modified DNA was amplified using a methylation-specific or unmethylation-specific primer pair (Supplementary Table 3) that had been previously confirmed not to amplify nonbisulfite-modified DNA. For bisulfite sequencing PCR (BSP), bisulfite-treated DNA was amplified using BSP primers (Supplementary Table 3), and the amplified products were cloned into a $\mathrm{pMD}^{\circledR} 18-\mathrm{T}$ vector (TaKaRa). Fourteen colonies for each sample were randomly chosen for sequencing.

For the sperm from the patients and controls, the BSP-amplified products were divided into two aliquots: one was subjected to electrophoresis through a $1.5 \%$ agarose gel and stained with ethidium bromide, and the other was cloned into a pEASY-T3 vector (TransGen Biotech, Beijing, China), and 16 colonies for each sample were randomly chosen for sequencing.

\section{Detection of the HBV $X \& S$ gene transcription using reverse transcription PCR \& real-time quantitative PCR}

Total RNA was extracted from sperm transfected with plasmids, as well as from sperm from the patients and controls and from sperm-derived embryos, using TRIzol reagent (Life Technologies, CA, USA). The cDNA was synthesized with a PrimeScript ${ }^{\mathrm{TM}}$ RT Reagent Kit with gDNA Eraser (Cat. \#RR047A; Takara Biotech, Dalian, China) according to the manufacturer's protocol.

Reverse transcription PCR (RT-PCR) was performed in a $20 \mu \mathrm{l}$ reaction volume using a QuantiFast $^{\mathrm{TM}} \mathrm{SYBR}^{\circledR}$ Green PCR Kit (Qiagen, Hilden, Germany). Human/mouse $\beta$-actin genes were used as internal control genes for the sperm/embryo samples, respectively. The primer pairs used for $\beta$-actin and the HBV $X$ and $S$ genes are shown in Supplementary Table 3. The cycling conditions were as follows: $5 \mathrm{~min}$ at $95^{\circ} \mathrm{C}$, followed by 40 cycles of $15 \mathrm{~s}$ at $95^{\circ} \mathrm{C}$ and $30 \mathrm{~s}$ at $60^{\circ} \mathrm{C}$. The amplified PCR fragments were subjected to electrophoresis through a $1.5 \%$ agarose gel and stained with ethidium bromide.

Real-time quantitative PCR (qRT-PCR) was performed using a QuantiFast SYBR ${ }^{\circledR}$ Green PCR Kit (QIAGEN, Shanghai, China) according to the manufacturer's instructions. GAPDH was used as an internal control gene. The $20 \mu \mathrm{l}$ reaction mixture contained cDNA template $(2 \mu \mathrm{l}), 2 \times$ QuantiFast SYBR $^{\circledR}$ Green PCR Master Mix $(10 \mu \mathrm{l})$, the forward and reverse primers (10 mM, $0.4 \mu \mathrm{l} \mathrm{each)} \mathrm{and} \mathrm{RNase-free} \mathrm{water}(7.2 \mu \mathrm{l})$. The primer pairs used for GAPDH and the HBV $X$ and $S$ genes are shown in Supplementary Table 3. The realtime qPCR conditions were as follows: $50^{\circ} \mathrm{C}$ for $2 \mathrm{~min}$ 
and $95^{\circ} \mathrm{C}$ for $5 \mathrm{~min}$, followed by 40 cycles of $95^{\circ} \mathrm{C}$ for $15 \mathrm{~s}$ and $60^{\circ} \mathrm{C}$ for $30 \mathrm{~s}$. Data analysis for singleplex assay was performed using an ABI 7300 PCR Thermal Cycler and ABI 7300 SDS software v1.4.0 (ABI, CA, USA).

\section{Treatment with SAM}

After fertilization of zona-free hamster oocytes with patient sperm, inseminated ova were divided into two groups. In the treatment group, SAM $(8 \mathrm{mM}, 1 \mu \mathrm{l})$ was added to a droplet $(50 \mu \mathrm{l}$ each) of ovum culture medium (Flow Laboratories, Germany) containing the inseminated ova at the beginning of postinsemination culturing. For the control group, no SAM was added. After incubation for $24 \mathrm{~h}$, two-celled embryos were collected to detect the methylation statuses of the $\mathrm{CpG}$ sites in islands II and III using BSP and to assess the transcriptional levels of the HBV $X$ and $S$ genes using real-time qRT-PCR and the $2^{-\Delta \Delta C t}$ method.

\section{Statistical analysis}

The Spearman's correlation analysis and graphing were performed using GraphPad Prism 7 software to assess the associations between the transcriptional levels of the HBV $X$ and $S$ genes and the methylation percentages of $\mathrm{CpG}$ sites in islands II and III in the HBV genome, respectively, in the sperm and spermderived embryos. The Wilcoxon signed rank test for paired samples was performed using SPSS 16.0 software to identify significant differences in the average methylation percentages of CpG sites in islands II and III between the sperm and sperm-derived embryos. A p-value of $<0.05$ was considered significant.

\section{Results}

HBV genes in plasmid-transfected sperm \& sperm-derived embryos

Methylation statuses of CpG sites in islands II \& III in the HBV genome

Transfection efficiency

Human sperm samples were transfected with a plasmid, pBR322-HBV, which was either unmethylated or methylated. The transfection efficiencies of the unmethylated and methylated plasmids into the sperm were $36.8 \pm 2.67 \%$ and $33.9 \pm 1.86 \%$, respectively. There was no significant difference in transfection efficiency between the two plasmids ( $\mathrm{p}>0.05$ ).

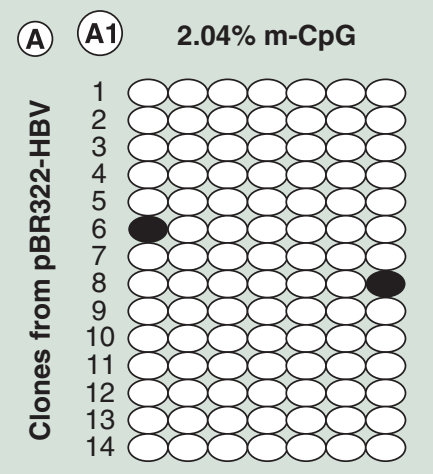

(B) (B1) $0.89 \% \mathrm{~m}-\mathrm{CpG}$

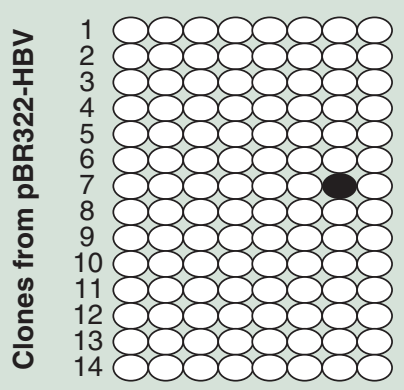

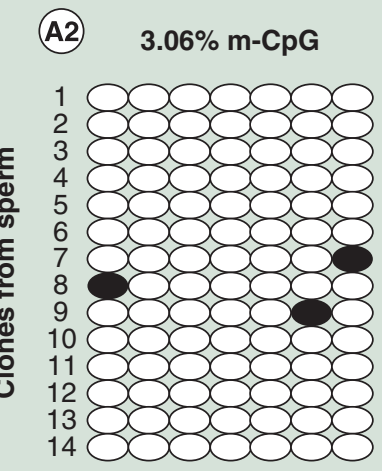

(B2) $1.78 \% \mathrm{~m}-\mathrm{CpG}$

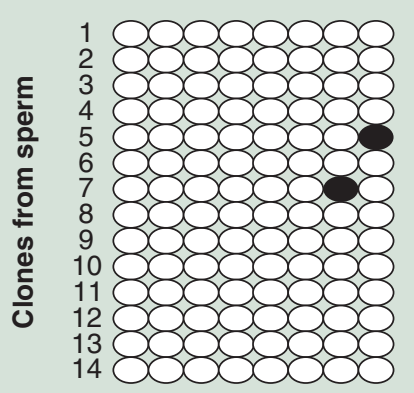

(A3) $2.04 \% \mathrm{~m}-\mathrm{CpG}$

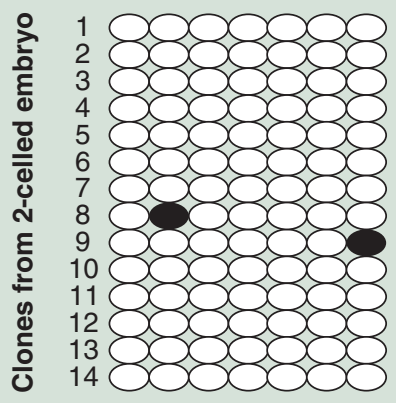

(B3) $0.89 \% \mathrm{~m}-\mathrm{CpG}$

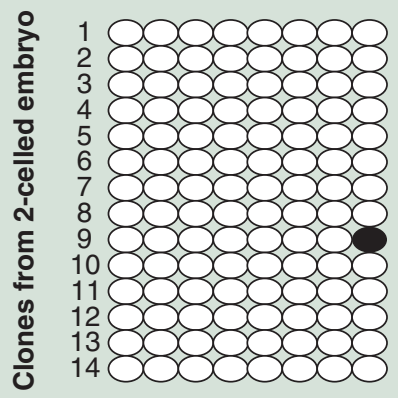

Figure 1. CpG site methylation in islands II and III in the hepatitis B virus genome in sperm transfected with an unmethylated plasmid and in sperm-derived embryos, as detected by bisulfite sequencing PCR. (A) Detection of CpG site methylation in island II. (A1) in plasmid; (A2) in sperm; and (A3) in sperm-derived embryo. (B) Detection of CPG site methylation in island III. (B1) in plasmid; (B2) in sperm; and (B3) in sperm-derived embryo. The methylation statuses of 14 clones for each sample are presented; each column represents one $\mathrm{CpG}$ position in island II or III, and each circle in the column indicates either cytosine (open circles) or methyl cytosine (filled circles). 
(A) A1 $96.93 \% \mathrm{~m}-\mathrm{CpG}$

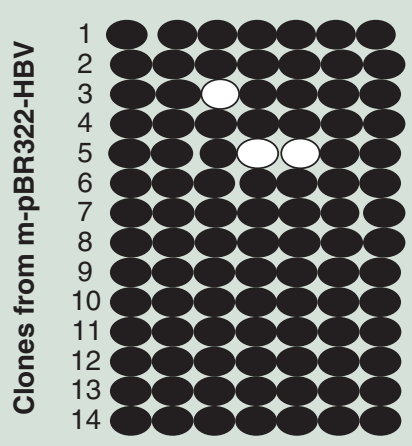

(B) (B1) $95.5 \% \mathrm{~m}-\mathrm{CpG}$

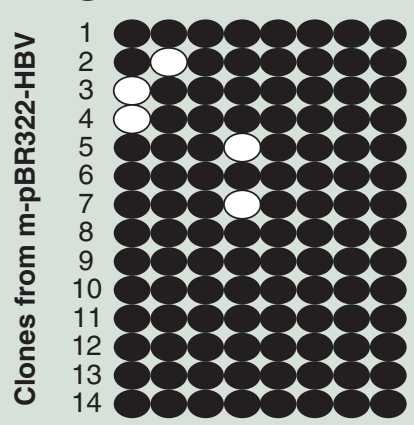

$95 \% \mathrm{~m}-\mathrm{CpG}$

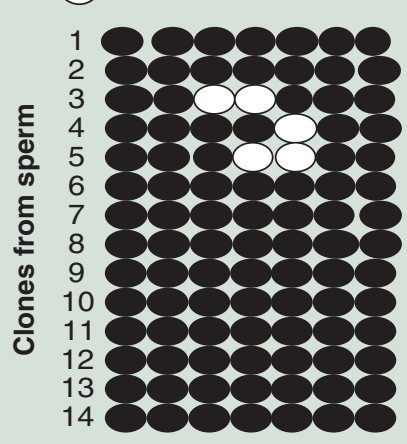

(B2) $82.14 \% \mathrm{~m}-\mathrm{CpG}$

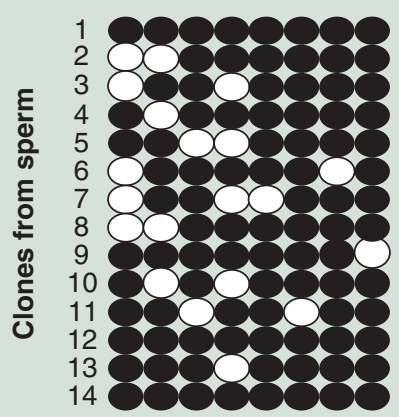

(A3) $3.06 \% \mathrm{~m}-\mathrm{CpG}$

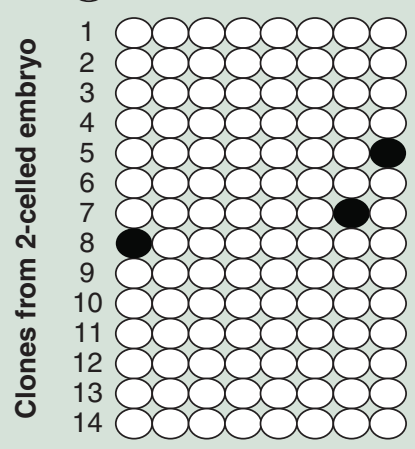

(B3) $1.78 \% \mathrm{~m}-\mathrm{CpG}$

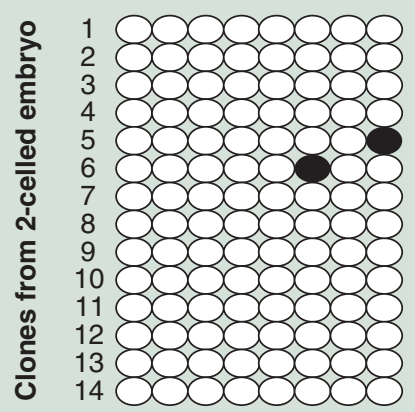

Figure 2. CpG site methylation in islands II and III in the hepatitis B virus genome in sperm transfected with a methylated plasmid and in sperm-derived embryos, as detected by bisulfite sequencing PCR. (A) Detection of CpG site methylation in island II. (A1) in plasmid; (A2) in sperm; and (A3) in sperm-derived embryo. (B) Detection of CpG site methylation in island III. (B1) in plasmid; (B2) in sperm; and (B3) in sperm-derived embryos.

Sperm transfected with the unmethylated plasmid

The BSP results showed that CpG sites in islands II and III in the HBV genome were hypomethylated in the unmethylated plasmid and in the sperm and sperm-derived embryos; the methylation percentages were $2.04,3.06$ and $2.04 \%$ for island II and 0.89 , 1.78 and $0.89 \%$ for island III, respectively (Figure 1).

Sperm transfected with the methylated plasmid

The methylation statuses of $\mathrm{CpG}$ sites in islands II and III in the HBV genome were analyzed by MSP. For the methylated plasmid, the $\mathrm{M}$ product, which was amplified using a methylationspecific primer, was observed in islands II and III but not in the negative control. The $\mathrm{U}$ product, which was amplified using an unmethylatedspecific primer, was not detected in either island (Supplementary Figure 3A). In the sperm, only the $M$ product was observed in island II, but both the $\mathrm{M}$ and $\mathrm{U}$ products were observed in island III. Neither the $\mathrm{M}$ nor the $\mathrm{U}$ product was detected in the negative control (Supplementary Figure $3 \mathrm{~B}$ ). In the sperm-derived embryos, only the $U$ product was observed in both islands but not in the negative control (Supplementary Figure 3C).

The methylation statuses of $\mathrm{CpG}$ sites in islands II and III in the HBV genome were further analyzed by BSP. These sites were hypermethylated in the methylated plasmid, with methylation percentages of 96.93 and $95.5 \%$, respectively (Figure $2 \mathrm{~A} 1$ \& $2 \mathrm{~B} 1$ ). In the transfected sperm, CpG sites in island II were also hypermethylated, with a methylation percentage of $95 \%$ (Figure 2A2), but some sites in island III were demethylated, with a decrease in the methylation percentage from 95.5 to $82.14 \%$ (Figure 2B2). In the sperm-derived embryos, most $\mathrm{CpG}$ sites in both islands II and III were demethylated, with methylation percentages of 3.06 and $1.78 \%$, respectively (Figure 2A3 \& B3).

\section{Transcription of the HBV X and S genes in} transfected sperm \& sperm-derived embryos A positive band for the internal control gene ( $\beta$-actin) was observed by RT-PCR for both sperm and spermderived embryos. However, only a positive band for 


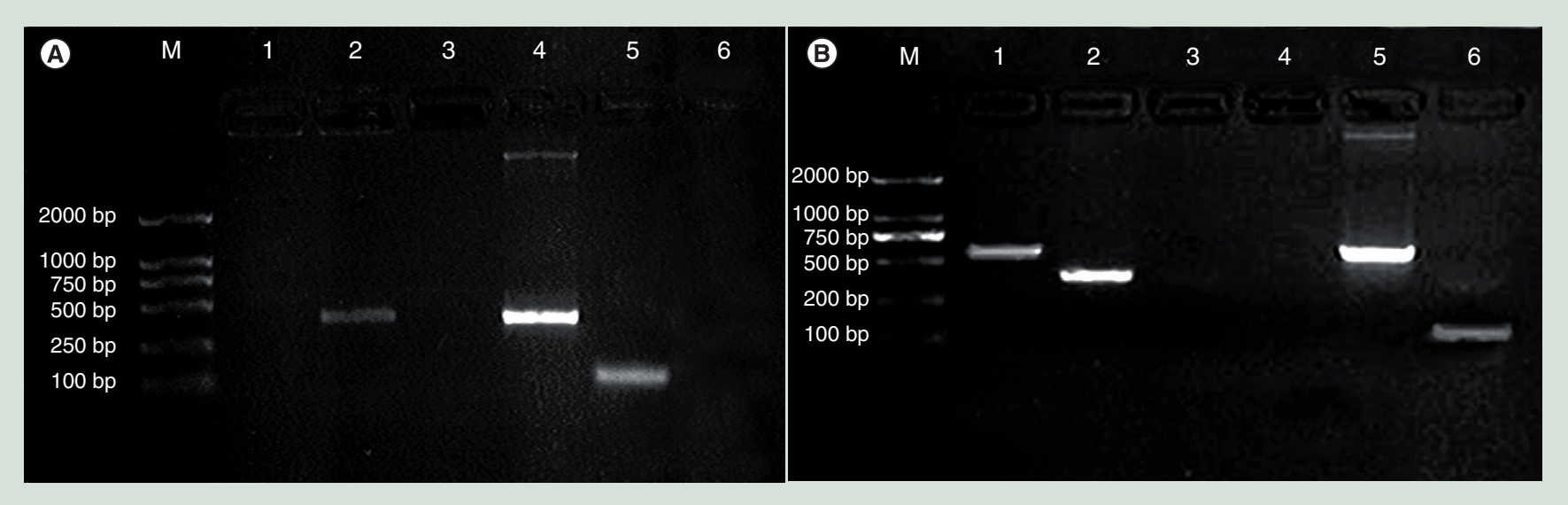

Figure 3. Transcription of the HBV $X$ and HBV $S$ genes in sperm transfected with a methylated plasmid and in sperm-derived embryos. (A) In sperm. M: marker DL2000; 1: X gene; 2: S gene; 3: -RT; 4: positive control; 5: $\beta$-actin; and 6: -T. (B) In sperm-derived embryos. M: marker DL2000; 1: X gene; 2: S gene; 3: -T; 4: -RT; 5: positive control; and 6: $\beta$-actin.

the $S$ gene was observed for the sperm (Figure 3A), and positive bands for both the $X$ and $S$ genes were detected for the sperm-derived embryos (Figure $3 \mathrm{~B}$ ).

The effects of $\mathrm{CpG}$ site methylation on the transcriptional levels of the $X$ and $S$ genes in human sperm and sperm-derived embryos were further assessed by real-time qRT-PCR and the $2^{-\triangle \Delta C T}$ method. The transcriptional levels of these genes in the sperm transfected with the methylated plasmid were significantly lower than those in the sperm transfected with the unmethylated plasmid. The transcriptional levels of the $X$ and $S$ genes decreased by 8333 - and 11.63fold, respectively, in the sperm transfected with the methylated plasmid compared with that transfected with the unmethylated plasmid (Table 1). These levels were very similar between embryos derived from sperm transfected with the methylated plasmid and those derived from sperm transfected with the unmethylated plasmid (Table 1), with no significant differences detected $(\mathrm{p}>0.05)$.
HBV genes in patient sperm \& sperm-derived embryos

Methylation statuses of CpG sites in islands II \& III in the HBV genome

Gel electrophoresis of the BSP-amplified products revealed the presence of methylation-specific bands for CpG sites in islands II and III in the sperm from the 11 HBV patients but not in that from the 11 controls. The sizes of the amplified products were 132 and $112 \mathrm{bp}$ for islands II and III, respectively (Figure 4).

The sequencing results for the BSP-amplified products showed variable methylation percentages of $\mathrm{CpG}$ sites in islands II and III in the sperm from the $11 \mathrm{HBV}$ patients, with mean values of $56.66 \pm 35.27 \%$ (range of 9.82 to $95.54 \%$ ) and $62.43 \pm 32.42 \%$ (range of 10.16 to $96.09 \%$ ), respectively. After fertilization, the CpG sites in islands II and III were highly demethylated, with mean values of $3.33 \pm 2.37 \%$ (range of 0.89 to $8.04 \%$ ) and $3.20 \%$ $\pm 2.48 \%$ (range of 0.78 to $7.81 \%$ ) in the sperm-derived embryos, respectively (Supplementary Figure 4; Table 2).

Table 1. Effects of the methylation statuses of $\mathrm{CpG}$ sites on the transcriptional levels of the hepatitis $B$ virus $X$ and $S$ genes in human sperm transfected with an unmethylated and a methylated plasmids and in sperm-derived embryos, respectively.

\begin{tabular}{|c|c|c|c|c|c|c|}
\hline \multirow[t]{2}{*}{ Samples } & \multicolumn{3}{|c|}{$\mathrm{HBV} X\left(2^{-\Delta \Delta C T}\right)$} & \multicolumn{3}{|c|}{ HBV S $\left(2^{-\Delta \Delta C T}\right)$} \\
\hline & $\mathbf{M}$ & Un-M & FCV & $\mathbf{M}$ & Un-M & FCV \\
\hline Sperm & $1.2 \times 10^{-4 * * *}$ & 1.00 & -8333 & $0.086^{* * *}$ & 1.00 & -11.63 \\
\hline Sperm-derived embryo & $0.96 *$ & 1.00 & 0.96 & $0.96 *$ & 1.00 & 0.96 \\
\hline \multicolumn{7}{|c|}{$\begin{array}{l}{ }^{*} p>0.05 . \\
* * * p<0.0001 . \\
\text { Real-time qRT-PCR and the } 2^{-\Delta \Lambda C T} \text { methods were used to evaluate effects of the methylation statuses of CpG sites on the transcriptional } \\
\text { levels of the } X \text { and } S \text { genes in human sperm transfected with an unmethylated or a methylated plasmid and in sperm-derived embryos, } \\
\text { respectively. The data were presented as an FCV in transcription of the } X \text { and } S \text { genes in the } M \text { normalized to internal control gene (GAPDH) } \\
\text { and relative to those in the Un-M. The individual data were converted into a linear form using } 2^{-\Delta \Lambda C T} \text { calculation and then subjected to a } \\
\text { paired-sample t test to determine whether there was a significant difference in average transcriptional levels of the } X \text { and } S \text { genes between } \\
\text { the methylated and unmethylated groups. A p-value of less than } 0.05 \text { was considered significant. } \\
\text { FCV: Fol change value; M: Methylated group; Un-M: Unmethylated group. }\end{array}$} \\
\hline
\end{tabular}




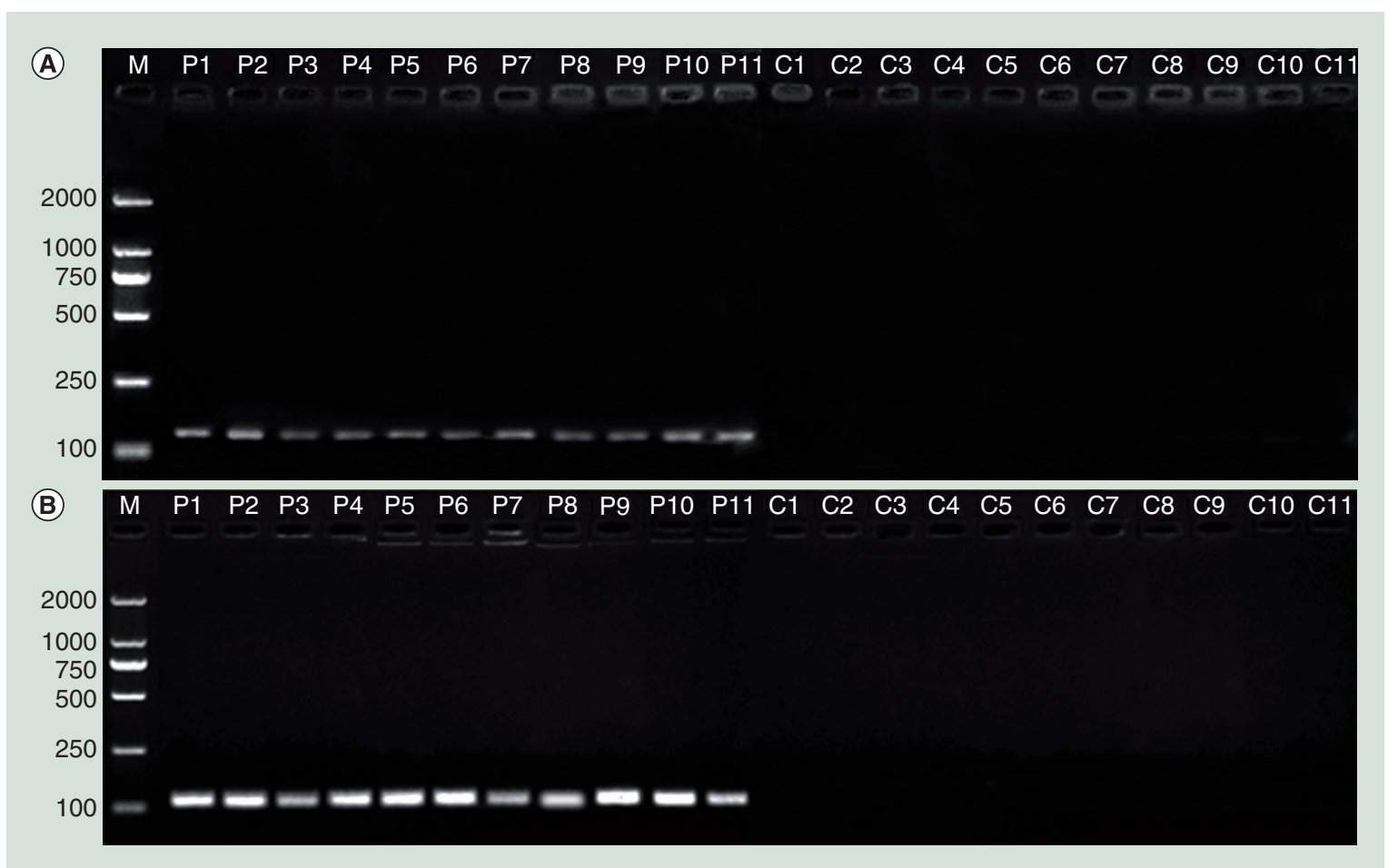

Figure 4. For sperm from the hepatitis B virus-infected patients and controls, aliquots of the bisulfite sequencing PCR amplified products were subjected to electrophoresis through a $1.5 \%$ agarose gel and stained with ethidium bromide. Methylation-specific bands for CPG sites in island II (A) and island III (B) in the hepatitis B virus genome were observed for the patient sperm but not for the control sperm.

C1-C11: Sperm from controls; M: Marker; P1-P11: Sperm from the patients.

The mean values significantly differed between the sperm and sperm-derived embryos $(\mathrm{p}<0.01)$.

\section{Transcriptional levels of the HBV X \& S genes}

The transcriptional levels of the $X$ and $S$ genes increased with the decreases in the methylation percentages of CpG sites in islands II and III, respectively, in the sperm from the 11 patients and in the sperm-derived embryos (Figure 5 \& Table 2). A strong negative correlations was detected between the methylation percentages and transcriptional levels for both the sperm $(\mathrm{r}=-1, \mathrm{p}<0.0001$ for $X$ gene; $\mathrm{r}=-0.9909, \mathrm{p}<0.0001$ for $S$ gene) and sperm-derived embryo $(r=-0.9623, p<0.0001$ for $X$ gene; $\mathrm{r}=-0.9745, \mathrm{p}<0.0001$ for $S$ gene).

\section{Effects of SAM on the methylation statuses of} CpG sites in islands II \& III \& on the transcriptional levels of the HBV $X \& S$ genes

The methylation percentages of $\mathrm{CpG}$ sites in islands II and III in SAM-treated embryos were markedly increased (61.61 and 55.47\%) compared with those in untreated embryos (1.79 and 0.78\%) (Figure 6). Further, the transcriptional levels of the $X$ and $S$ genes decreased by 2.13- and 2.04-fold, respectively, in the SAM-treated embryos compared with the untreated embryos (Table 3).

\section{Discussion}

In the current study, two measures were taken to ensure reliable and accurate results. First, combined bioinformatic and experimental analysis was performed. Given that HBV DNA contains three conventional CpG islands (I, II and III) [23-26], we searched GenBank of the NCBI and retrieved three normal HBV sequences (accession numbers: EU871997, AY206384 and AY123424) for use as reference sequences. We then verified the locations and sizes of islands I, II and III in the representative HBV genomic sequences. The relationships between $\mathrm{CpG}$ site methylation in island II and III and the transcriptional levels of the $X$ and $S$ genes in sperm and sperm-derived embryos were then investigated using experimental methods. Next, combined in vitro and an in vivo experiment was performed. For the in vitro experiment, sperm from healthy donors was transfected with either an unmethylated or a methylated plasmid, pBR322-HBV, containing the full-length HBV genome. This allowed for determination of differences in the methylation statuses of $\mathrm{CpG}$ sites in the $\mathrm{HBV}$ genome and for assessment of the effects of such differences on the regulation of HBV gene expression in sperm and spermderived embryos. For the in vivo experiment, we performed analysis using sperm cells from HBV-infected 
Table 2. Methylation percentages ( $\mathrm{mCpG} \%$ ) of $\mathrm{CpG}$ sites in islands II and III, and the transcriptional levels of the hepatitis $B$ virus $X$ and $S$ genes in the patient sperm and sperm-derived embryos.

\begin{tabular}{|c|c|c|c|c|c|c|c|c|}
\hline \multirow[t]{3}{*}{ Patients } & \multicolumn{4}{|c|}{ CpG sites in island II/HBV $X$ gene } & \multicolumn{4}{|c|}{ CpG sites in island III/HBV S gene } \\
\hline & \multicolumn{2}{|c|}{ Sperm } & \multicolumn{2}{|c|}{ Two-celled embryos } & \multicolumn{2}{|c|}{ Sperm } & \multicolumn{2}{|c|}{ Two-celled embryos } \\
\hline & $\mathrm{mCpG} \%$ & $2^{-\triangle \Lambda C T}$ & mCpG\% & $2^{-\triangle \Delta C T}$ & mCpG\% & $2^{-\triangle \Delta C T}$ & mCpG\% & $2^{-\triangle \triangle C T}$ \\
\hline 2\# & 95.54 & 1.00 & 8.04 & 1.00 & 96.09 & 1.00 & 7.81 & 1.00 \\
\hline $5 \#$ & 91.96 & 1.35 & 6.25 & 1.16 & 93.75 & 1.32 & 6.25 & 1.08 \\
\hline 7\# & 89.29 & 1.81 & 5.36 & 1.17 & 92.19 & 1.59 & 5.47 & 1.13 \\
\hline 8\# & 88.39 & 2.10 & 4.46 & 1.18 & 89.84 & 1.93 & 4.69 & 1.15 \\
\hline 1\# & 83.93 & 2.47 & 2.68 & 1.20 & 86.72 & 2.25 & 3.13 & 1.15 \\
\hline $10 \#$ & 64.29 & 4.58 & 2.68 & 1.21 & 71.09 & 4.21 & 2.34 & 1.17 \\
\hline $11 \#$ & 44.64 & 6.38 & 1.79 & 1.22 & 55.47 & 5.76 & 1.56 & 1.17 \\
\hline 3\# & 25.89 & 12.56 & 1.79 & 1.23 & 40.63 & 11.67 & 1.56 & 1.18 \\
\hline 4\# & 17.86 & 21.66 & 1.79 & 1.23 & 25.00 & 20.59 & 0.78 & 1.18 \\
\hline 9\# & 11.61 & 24.04 & 0.89 & 1.23 & 24.22 & 19.57 & 0.78 & 1.19 \\
\hline $6 \#$ & 9.82 & 34.81 & 0.89 & 1.23 & 10.16 & 28.56 & 0.78 & 1.19 \\
\hline Mean & $56.66 \pm 35.27$ & 10.25 & $3.33 \pm 2.37$ & 1.19 & $62.43 \pm 32.42$ & 8.95 & $3.20 \pm 2.48$ & 1.14 \\
\hline \multicolumn{9}{|c|}{$\begin{array}{l}\text { Using real-time } q R T-P C R \text { and the } 2^{-\Delta C T} \text { methods, the data were presented as a fold change in transcriptional levels of the } X \text { or } S \text { genes in the } \\
\text { sperm from the } 11 \text { patients and in the sperm-derived embryos normalized to an endogenous reference gene }(G A P D H) \text { and relative to those } \\
\text { of the } X \text { or } S \text { gene in the sperm and sperm-derived embryo with the highest level of } C p G \text { sitemethylation, respectively. } \\
\text { HBV: Hepatitis B virus. }\end{array}$} \\
\hline
\end{tabular}

patients to obtain more accurate results regarding $\mathrm{CpG}$ site methylation and HBV gene transcription in these patients. Furthermore, the interspecific in vitro fertilization was employed in the current study to obtain two-celled embryos. Although using embryo produced by fertilization between human oocyte and human sperm that carries HBV genes would be an ideal model, such a model presents major moral, ethical and legal problems, and is not allowed to use. The interspecific in vitro fertilization between human sperm and zona-free golden hamster ova is highly associated with human in vitro fertilization as well as avoids the aforementioned problems. Thus this model has been widely used in the research area of reproductive biology and medicine [4-7,15-18,32-36] and included in the "WHO laboratory manual for the Examination and processing of human semen" [37], and recognized by the academic circles.

Methylation statuses of $\mathrm{CpG}$ sites in the HBV genome in transfected sperm

CpG sites in islands II and III in the HBV genome were hypomethylated in the unmethylated plasmid (2.04 and $0.89 \%)$. Transfection of the plasmid into sperm did not result in a significant change in the methylation status (3.06 and 1.78\%). These findings suggest that there is no mechanism for de novo methylation of HBV CpG sites in mature sperm, which may be related to that mature sperm lose most of their cytoplasm, as well as DNA methyltransferases during the process of spermatogenesis [38,39].

CpG sites in islands II and III in the HBV genome were hypermethylated in the methylated plasmid (96.93 and $95.5 \%$ ). However, interestingly, when this plasmid was transfected into sperm, the CpG sites in island II were still hypermethylated (95\%), but those in island III showed a decrease in the methylation percentage from 95.5 to $82.14 \%$. These findings suggested that some CPG sites in island III were demethylated in the mature sperm, which are in accordance with the results of MSP assay. Using MSP assay, only the methylation-specific primer successfully amplified a methylated product in island II. In contrast, both the methylation- and unmethylation-specific primers successfully amplified methylated and unmethylated products, respectively, in island III. Similar results have been observed in a previous study [40]. Further investigation is required to determine whether a demethylation mechanism exists for some viral CpG sites in mature sperm.

\section{Methylation statuses of $\mathrm{CpG}$ sites in the HBV genome in patient sperm \& sperm-derived embryos}

CpG sites in the HBV genome can be methylated in sperm cells before maturation

In the current study, positive methylation bands for CpG sites in islands II and III in the HBV genome were detected in all sperm samples from the $11 \mathrm{HBV}$ - 
infected patients but not in those from the 11 controls. CpG islands are normally unmethylated $[21,41]$; therefore, these results indicate that $\mathrm{CpG}$ sites in the HBV genome can be methylated by the cellular DNA methylation machinery in human male germ cells, as observed in human liver tissues [26-28]. However, as mentioned above, CpG sites in the HBV genome could not be methylated in mature sperm. Thus we speculated that CpG site methylation in the HBV genome in patient sperm might occur prior to the elongation stage in the spermatid nucleus not in mature sperm.

The DNA methylation level is associated with multiple factors, including the induction of DNA methyltransferase activity, short hairpin RNA, and

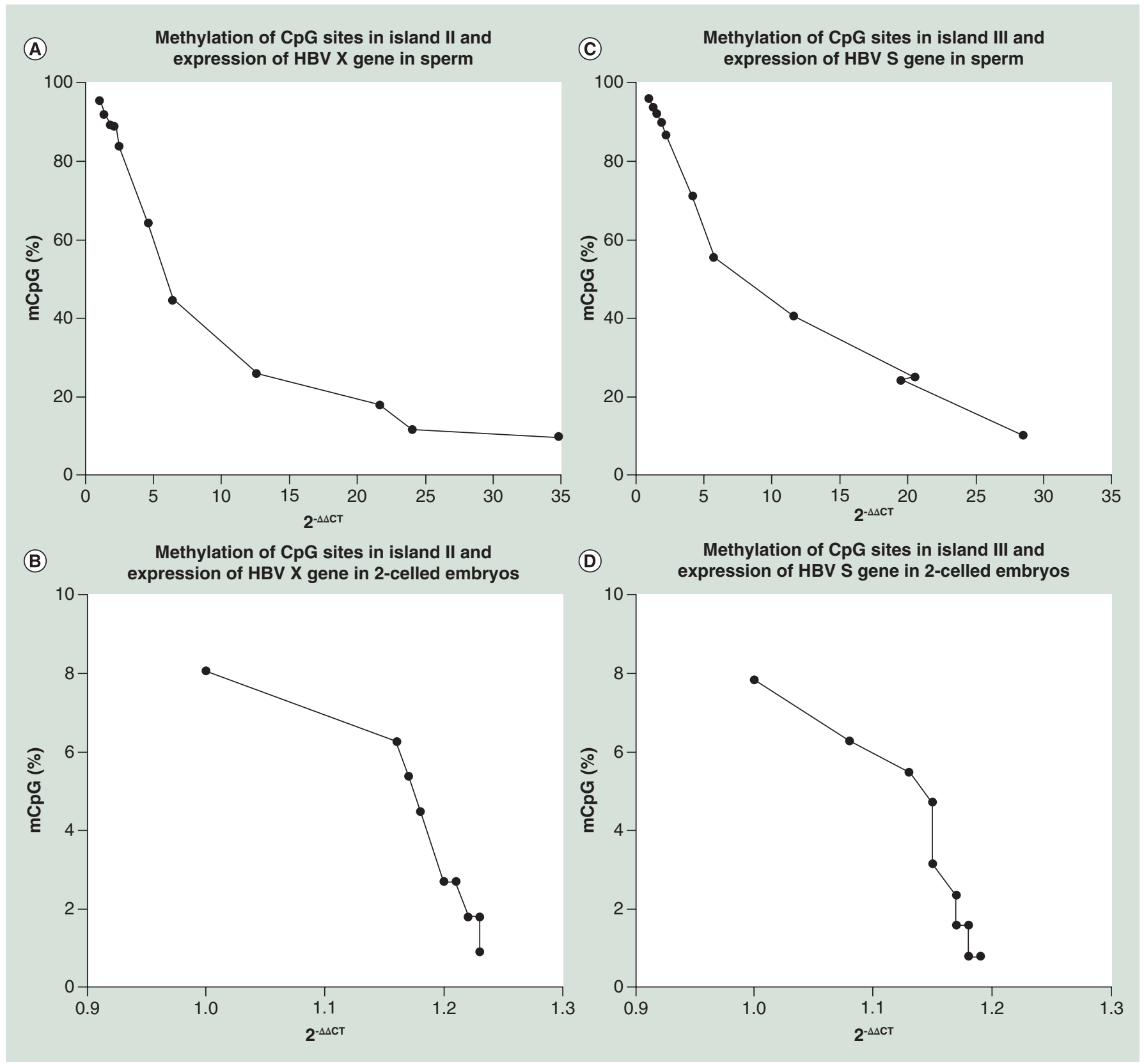

Figure 5. Correlation between the methylation percentages (mCpG\%) of CpG sites in islands II and III in the hepatitis B virus genome and the transcriptional levels $\left(2^{-\Delta \Delta C t}\right)$ of the hepatitis B virus $X$ and $S$ genes in patient sperm and sperm-derived embryos. The transcriptional levels of the $X$ and $S$ genes increased with decreases in the methylation percentages of CpG sites in islands II and III, respectively, and strong negative correlations were observed. (A) $X$ gene/island II correlation in sperm (Spearman's $r=-1 ; p<0.0001$ ); (B) $X$ gene/island II correlation in sperm-derived embryos (Spearman's $r=-0.9623 ; p<0.0001$ ); (C) $S$ gene/island III correlation in sperm (Spearman's $r=-0.9909 ; p<0.0001$ ); and (D) S gene/island III correlation in sperm-derived embryos (Spearman's $r=-0.9745$; $\mathrm{p}<0.0001)$. 


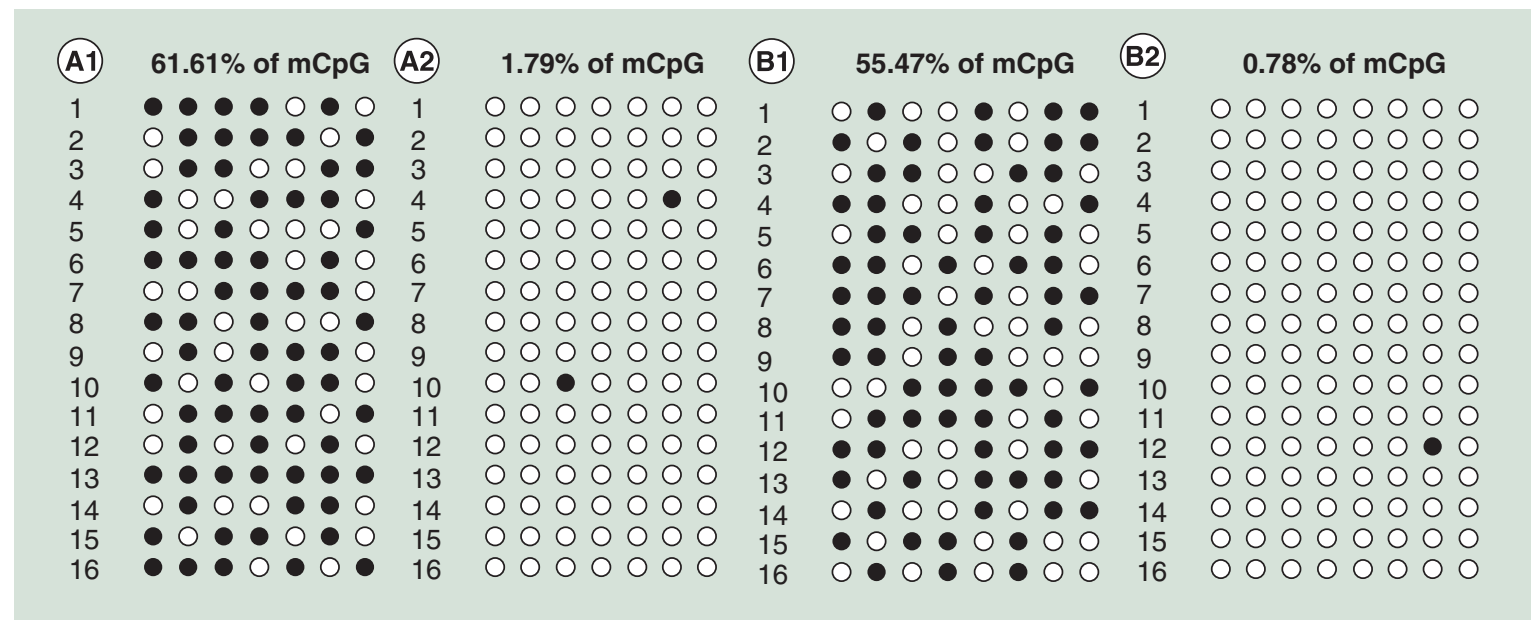

Figure 6. Effects of S-adenosylmethionine on the methylation of CpG sites in islands II and III in embryos.

(A1) Island II with S-adenosylmethionine (SAM); (A2) island II without SAM; (B1) island III with SAM; and

(B2) island III without SAM. The results showed that the methylation percentages of CpG sites in islands II and III in the embryos markedly increased following treatment with SAM.

methyl-binding domain-containing proteins and DNA glycosylases activities [21,42]. The activities of such factors varied among the $\mathrm{HBV}$-infected patients, which might be the reason for the differences in the methylation percentages of the $\mathrm{CpG}$ sites in the $\mathrm{HBV}$ genome among the 11 patients.

Methylation patterns of $\mathrm{CpG}$ sites in the HBV genome during transmission from patient sperm to sperm-derived embryos

In male germ cells, methylation begins in prospermatogonia and persists throughout spermatogenesis $[43,44]$. After fertilization, active demethylation of the paternal genome in the zygote occurs before DNA replication. This process is followed by passive demethylation during the cleavage stage, and de novo methylation has been proposed to occur after implantation [45-47]. In the current study, after fertilization, the CpG sites in islands II and III in the HBV genome in both the patient sperm and HBV-transfected sperm were significantly demethylated $(p<0.01)$. These results suggest that the demethylation of $\mathrm{CpG}$ sites in islands II and III in the HBV genome is synchronous with active demethylation of the host genome in sperm-derived embryos. In the host genome, the preferential demethylation of paternal DNA in zygotes is a general phenomenon. One study has reported that the components of the elongator complex (Elp1, Elp3 and Elp4) are important for paternal DNA demethylation [46]. Notably, further studies are needed to determine whether there is any correlation between these factors and the mechanism underlying demethylation in the HBV genome in zygotes and preimplantation embryos.

\section{Relationship between transcription of the} HBV $X$ \& $S$ genes \& methylation of CpG sites in islands II \& III in host sperm \& sperm-derived embryos

In the current study, the results of the in vitro and in vivo experiments showed that the transcriptional levels of the $X$ and $S$ genes increased with decreases in the methylation percentages of CpG sites in islands II and III, respectively, in both the sperm and sperm-derived embryos. In addition, strong negative correlations were observed between the methylation percentages and transcriptional levels. These findings indicate that CpG site methylation in islands II and III in the HBV

Table 3. Transcriptional levels of the hepatitis B virus $X$ and $S$ genes in the embryos treated and untreated with $\mathrm{S}$-adenosylmethionine.

\begin{tabular}{|c|c|c|c|}
\hline Genes & Treatment with SAM $2^{-\triangle \Lambda C T}$ & Treatment without SAM $2^{-\triangle \triangle C T}$ & Fold change value \\
\hline HBV $X$ gene & $0.47(0.43-0.51)$ & $1(0.67-1.33)$ & -2.13 \\
\hline HBV S gene & $0.49(0.45-0.53)$ & $1(0.74-1.26)$ & -2.04 \\
\hline \multicolumn{4}{|c|}{$\begin{array}{l}\text { Real time } q R T-P C R \text { and the } 2^{-\triangle A C T} \text { methods were used to evaluate the effects of SAM treatment on expression of the } X \text { and } S \text { genes in the } \\
\text { embryos. The data were presented as the fold change value in expression of the } X \text { and } S \text { genes in SAM-treated group normalized to internal } \\
\text { control gene (GAPDH) and relative to those in SAM-untreated group. } \\
\text { HBV: Hepatitis B virus; SAM: S-adenosylmethionine. }\end{array}$} \\
\hline
\end{tabular}


genome plays roles in transcriptional regulation of the $X$ and $S$ genes, respectively, in sperm and sperm-derived embryos.

SAM, the classical methyl donor of numerous methylation reactions, inhibits active demethylation [48]. In the current study, the treatment of embryos with SAM induced the hypermethylation of $\mathrm{CpG}$ sites in islands II and III in the HBV genome and correspondingly decreased the transcriptional levels of the $X$ and $S$ genes by 2.13 - and 2.04-fold, respectively, compared with the control treatment. These results further confirm that CPG site methylation in islands II and III in the HBV genome regulates transcription of the $X$ and $S$ genes, respectively.

To date, it remains uncertain which CpG island contributes to the regulation of surface gene expression. Island I spans the ATG start sites of surface antigen genes, and theoretically, it should be associated with surface gene expression. However, it has been reported that approximately $50 \%$ of the HBV sequences isolated from patients residing in 48 different countries lack island I [23]; this island has been detected only in $19.7 \%$ of the sequences isolated from Chinese patients with HBV genotype C [24], and it has not been detected in those isolated from European patients with genotype E and G [25]. Nonetheless, the regulation of surface gene expression still occurs in such patients lacking island I. Thus, it is unclear which island participates in regulating surface gene expression. In the current study, the results of the in vitro and in vivo experiments revealed a strong negative correlation between the transcriptional levels of surface genes and $\mathrm{CpG}$ site methylation in island III in sperm and sperm-derived embryos. These findings not only indicate that island III participates in the regulation of surface gene expression but also potentially explain the regulation mechanism of surface gene expression in $\mathrm{HBV}$ genomes lacking island I.

\section{Conclusion}

This study provides the first conclusive evidence that CpG sites in islands II and III in the HBV genome are methylated in sperm cells before maturation and are synchronously demethylated with active demethylation of the host genome in sperm-derived embryos. Transcrip- tional regulation of the HBV $X$ and $S$ genes is closely associated with the methylation of $\mathrm{CpG}$ sites in islands II and III in the HBV genome, respectively, which potentially explain the regulation mechanism of surface gene expression in HBV genomes lacking island I.

\section{Supplementary data}

To view the supplementary data that accompany this paper please visit the journal website at: http://www.futuremedicine.com/doi/full/10.2217/epi-2016-0129

\section{Financial \& competing interest disclosure}

This project was financially supported by the National Nature Science Foundation of China (Grant No. 30972627) and by the Applied Basic Research Program of Sichuan Province, China (Grant No. 2014JY0110). The funding bodies have no role in the design of the study and collection, analysis and interpretation of data and in writing the manuscript. The authors have no other relevant affiliations or financial involvement with any organization or entity with a financial interest in or financial conflict with the subject matter or materials discussed in the manuscript apart from those disclosed.

We thank American Journal Experts (AJE) for the English language editing, funded by Jinxin Research Institute for Reproductive Medicine and Genetics.

\section{Ethical conduct of research}

Semen samples were collected from healthy donors and patients with chronic HBV infection. Written informed consent was obtained from all subjects, permitting the use of their sperm samples for research purposes. All protocols involving human and animal subjects that were used in this study were approved by the Institutional Ethical Review Boards of Chengdu Jingjiang Hospital for Maternal and Child Health Care (approval number: (JHMCHC-0010) and by the Ethics Committee of Shantou University Medical College (Approval number: SUMC-00-0031), according to the recommended guidelines of the $\mathrm{NIH}$ involving human subjects and animal care and the 1975 Declaration of Helsinki.

\section{Open access}

This work is licensed under the Attribution-NonCommercialNoDerivatives 4.0 Unported License. To view a copy of this license, visit http://creativecommons.org/licenses/by-nc$\mathrm{nd} / 4.0 /$

\section{Executive summary}

- CpG sites in the hepatitis B virus (HBV) genome can be methylated in patient sperm cells before maturation.

- The demethylation of CpG sites in the HBV genome is synchronous with active demethylation of the host genome during transmission from patient sperm to sperm-derived embryos.

- Treatment of embryos with S-adenosylmethionine induced the hypermethylation of CpG sites in the HBV genome and correspondingly decreased the transcriptional levels of the HBV genes.

- Islands II and III participate in the regulation of the HBV $X$ and $S$ gene transcription, respectively, which potentially explain the regulation mechanism of surface gene expression in the HBV genome lacking island I. 


\section{References}

1 Davison F, Alexander GJ, Trowbridge R, Fagan EA, Williams R. Detection of hepatitis B virus DNA in spermatozoa: urine: saliva and leucocytes: of chronic $\mathrm{HBsAg}$ carriers. A lack of relationship with serum markers of replication. J. Hepatol. 4(1), 37-44 (1987).

2 Lang ZW. Distribution of hepatitis B virus in testicle tissue in patients with hepatitis B infection. Zhonghua Yi Xue Za Zhi 73(6), 329-331, 379 (1993).

3 Hadchouel M, Scotto J, Huret JL et al. Presence of HBV DNA in spermatozoa: a possible vertical transmission of HBV via the germ line. J. Med. Virol. 16, 61-66 (1985).

4 Huang JM, Huang TH, Qiu HY et al. Effects of hepatitis $\mathrm{B}$ virus infection on human sperm chromosomes. World J. Gastroenterol. 9(4), 736-740 (2003).

5 Ali BA, Huang TH, Xie QD. Detection and expression of hepatitis $\mathrm{B}$ virus $\mathrm{x}$ gene in one and two-cell embryos from golden hamster oocytes in vitro fertilized with human spermatozoa carrying HBV DNA. Mol. Reprod. Dev. 70(1), 30-36 (2005).

6 Ali BA, Huang TH, Salem HH, Xie QD. Expression of hepatitis $B$ virus genes in early embryonic cells originated from hamster ova and human spermatozoa transfected with the complete viral genome. Asian J. Androl. 8(3), 273-279 (2006).

7 Ahmed MM, Huang TH, Xie QD. An improved experimental model for studying vertical transmission of hepatitis B virus via human spermatozoa. J. Virol. Methods 151(1), 116-120 (2008).

8 Ganem D, Prince AM. Hepatitis B virus infection - natural history and clinical consequences. N. Engl. J. Med. 350 (11), 1118-1129 (2004).

9 Lee WM. Hepatitis B virus infection. N. Engl. J. Med. 337, 1733-1745 (1997).

10 Hu XL, Zhou XP, Qian YL, Wu GY, Ye YH, Zhu YM. The presence and expression of the hepatitis $\mathrm{B}$ virus in human oocytes and embryos. Hum. Reprod. 26(7), 1860-1867 (2011).

11 Wang S, Jiang P, Peng G. [Detection of S-gene mutation strain in vertical transmission of $\mathrm{HBV}$ and its significance]. Zhonghua Liu Xing Bing Xue Za Zhi 20, 204-207 (1999).

12 Wang S, Jiang P, Peng G. [HBV transmission from father to foetus and HBV DNA in tissues outside the liver]. Zhonghua Gan Zang Bing Za Zhi 7(4), 203-206 (1999).

13 Wang SS, Li MM, Peng GF et al. [HBV C gene mutation in the transmission from father to infant]. Zhonghua Er Ke Za Zhi 41, 845-848 (2003).

14 Wang SS, Li WL, Peng GF et al. [The analysis of S gene phylogenetic tree of $\mathrm{HBV}$ in transmission from father to infant]. Zhonghua Yi Xue Za Zhi 83(6), 451-454 (2003).

15 Wang D, Kang XJ, Li LB, Xie QD, Gao YS, Huang TH. In vitro study on vertical transmission of the HIV-1 gag gene by human sperm. J. Med. Virol. 83(1), 16-23 (2011).

16 Wang D, Li LB, Hou ZW et al. The integrated HIV-1 provirus in patient sperm chromosome and its transfer into the early embryo by fertilization. PLoS ONE 6(12), e28586 (2011).
17 Zhu Y, Ma M, Huang J et al. Effects of hepatitis C virus infection on human sperm chromosomes. Clin. Lab. 62(3), 373-379 (2016).

18 Ma M, Zhu Y, Wang D et al. Research on the vertical transmission of hepatitis $\mathrm{C}$ gene from father-to-child via human sperm. Clin. Lab. 62(1-2), 1-6 (2016).

19 Garolla A, Pizzol D, Bertoldo A, Menegazzo M, Barzon L, Foresta C. Sperm viral infection and male infertility: focus on HBV; HCV: HIV: HPV: HSV: HCMV: and AAV. J. Reprod. Immunol. 100(1), 20-29 (2013).

20 Oger P, Yazbeck C, Gervais A et al. Adverse effects of hepatitis $B$ virus on sperm motility and fertilization ability during IVF. Reprod. Biomed. Online 23(2), 207-212 (2011).

21 Law JA, Jacobsen SE. Establishing: maintaining and modifying DNA methylation patterns in plants and animals. Nat. Rev. Genet. 11(3), 204-220 (2010).

22 Kaur P, Paliwal A, Durantel D et al. DNA methylation of hepatitis $B$ virus (HBV) genome associated with the development of hepatocellular carcinoma and occult HBV infection. J. Infect. Dis. 202(5), 700-704 (2010).

23 Zhang Y, Li C, Zhang Y et al. Comparative analysis of CpG islands among HBV genotypes. PLoS ONE 8(2), e56711 (2013).

24 Hou Z, Huang J, Zhong C et al. CpG islands of hepatitis B virus genome isolated from Chinese patients. Gene 561(2), 261-267 (2015).

25 Zhong C, Hou Z, Huang J, Xie Q, Zhong Y. Mutations and $\mathrm{CpG}$ islands among hepatitis B virus genotypes in Europe. BMC Bioinformatics 16, 38 (2015).

26 Vivekanandan P, Thomas D, Torbenson M. Hepatitis B viral DNA is methylated in liver tissues. J. Viral. Hepat. 15(2), 103-107 (2008).

27 Tahara T, Arisawa T, Shibata T, Yamashita H, Yoshioka D, Hirata I. Effect of promoter methylation of multidrug resistance 1 (MDR1) gene in gastric carcinogenesis. Anticancer Res. 29(1), 337-341 (2009).

28 Chen JY, Hsu HC, Lee CS, Chen DS, Zuckerman AJ, Harrison TJ. Detection of hepatitis B virus DNA in hepatocellular carcinoma: methylation of integrated viral DNA. J. Virol. Methods 19(3-4), 257-263 (1988).

29 Reik W, Dean W, Walter J. Epigenetic reprogramming in mammalian development. Science 293(5532), 1089-1093 (2001).

30 Smallwood SA, Tomizawa S, Krueger F et al. Dynamic CpG island methylation landscape in oocytes and preimplantation embryos. Nat. Genet. 43(8), 811-814 (2011).

31 MethPrimer. www.urogene.org/methprimer/

32 Yanagimachi R, Yanagimachi H, Rogers BJ. The use of zona-free animal ova as a test-system for the assessment of the fertilizing capacity of human spermatozoa. Biol. Reprod. 15, 471-476 (1976).

33 Rudak E, Jacobs PA, Yanagimachi R. Direct analysis of the chromosome constitution of human spermatozoa. Nature 274(5674), 911-913 (1978).

34 Margalioth EJ, Navot D, Laufer N, Lewin A, Rabinowitz $\mathrm{R}$, Schenker JG. Correlation between the zona-free hamster 
egg sperm penetration assay and human in vitro fertilization. Fertil. Steril. 45(5), 665-670 (1986).

Margalioth EJ, Feinmesser M, Navot D, Mordel N, RBronson RA. The long-term predictive value of the zona-free hamster ova sperm penetration assay. Fertil. Steril. 52(3), 490-494 (1989)

36 Ford WC, Williams KM, Harrison $\mathrm{S}$ et al. Value of the hamster oocyte test and computerised measurements of sperm motility in predicting if four or more viable embryos will be obtained in an IVF cycle. Int. J. Androl. 24(2), 109-119 (2001).

37 WHO. WHO Laboratory Manual for the Examination and Processing of Human Semen (The 5th Edition). WHO Press, Geneva, Switzerland, 152-157 (2010).

Chen T, Ueda Y, Dodge JE, Wang Z, Li E. Establishment and maintenance of genomic methylation patterns in mouse embryonic stem cells by Dnmt3a and Dnmt3b. Mol. Cell Biol. 23(16), 5594-5605 (2003).

39 La Salle S, Trasler JM. Dynamic expression of DNMT3a and DNMT3b isoforms during male germ cell development in the mouse. Dev. Biol. 296(1), 71-82 (2006).

40 Li F, Li L, Zhong Y et al. Relationship between LTR methylation and gag expression of HIV-1 in human spermatozoa and sperm-derived embryos. PLoS ONE 8(1), e54801 (2013).

41 Rakyan VK, Down TA, Balding DJ, Beck S. Epigenomewide association studies for common human diseases. Nat. Rev. Genet. 12(8), 529-541 (2011).
42 Park HK, Min BY, Kim NY et al. Short hairpin RNA induces methylation of hepatitis B virus covalently closed circular DNA in human hepatoma cells. Biochem. Bioph. Res. Commun. 436(2), 152-155 (2013).

43 Davis TL, Yang GJ, McCarrey JR, Bartolomei MS. The H19 methylation imprint is erased and re-established differentially on the parental alleles during male germ cell development. Hum. Mol. Genet. 9(19), 2885-2894 (2000).

44 Kafri T, Ariel M, Brandeis M et al. Developmental pattern of gene-specific DNA methylation in the mouse embryo and germ line. Genes Dev. 6(5), 705-714 (1992).

45 Beaujean N, Taylor JE, McGarry M et al. The effect of interspecific oocytes on demethylation of sperm DNA. Proc. Natl Acad. Sci. USA 101(20), 7636-7640 (2004).

Okada Y, Yamagata K, Hong K, Wakayama T, Zhang Y. A role for the elongator complex in zygotic paternal genome demethylation. Nature 463(7280), 554-558 (2010).

47 Santos F, Hendrich B, Reik W, Dean W. Dynamic reprogramming of DNA methylation in the early mouse embryo. Dev. Biol. 241(1), 172-182 (2002). Detich N, Hamm S, Just G, Knox JD, Szyf M. The methyl donor $S$-adenosylmethionine inhibits active demethylation of DNA: a candidate novel mechanism for the pharmacological effects of S-adenosylmethionine. J. Biol. Chem. 278(23), 20812-20820 (2003). 